\title{
Determination of a Non-Linear Regression Model, to Describe the Relationship between the Resistance Measured with the Concrete Cylinder Compression Machine and a Digital Sclerometer
}

\author{
José Hernández Ávila ${ }^{1}$, Fernando Jove Wilches*1 and Rodrigo Hernández Avila ${ }^{1}$ \\ 1, Department of Civil Engineering, Universidad de Sucre, Sincelejo, Sucre, Colombia.
}

ORCIDs: 0000-0002-7557-9665 (José), 0000-0002-2080-4036 (Fernando), 0000-0003-3178-8075 (Rodrigo)

\begin{abstract}
The present study presents the results of applying an innovative and practical method to relate the compressive strength measured with the sclerometer and the compression machine, on concrete cylinders with ages of 3 days, 7 days, 14 days, 21 days and 28 days and design strengths of $17.5 \mathrm{MPa}, 21 \mathrm{MPa}$, 24.5 $\mathrm{MPa}$ and $28 \mathrm{MPa}$. Fine aggregate from the Sinú River (Lorica, Córdoba, Colombia) and coarse quarry aggregate (Toluviejo, Sucre, Colombia) were used to manufacture the concrete. The use of the sclerometer is proposed to estimate the resistance of concrete structures that are made of the aforementioned materials, and thus decrease the negative impact generated by the extraction of cores. For this purpose, the calibration curves of the equipment supplied by the supplier and the results obtained through a series of tests carried out were taken as comparative parameters.
\end{abstract}

Keywords: Compression machine, Sclerometer, Concrete, Compression Strength, Cylinders

\section{INTRODUCTION}

For more than 70 years, in the practice of concrete quality control, the simple compressive strength of concrete has been obtained through the compression resistance test on standard size cylinders. The test method is relatively easy to perform in terms of sampling, specimen preparation, and failure load determination. When done correctly, this test has low resistance variation within the laboratory, and therefore lends itself easily to being used as a standard. The final compression load thus obtained is modified by specified factors and used to verify the nominal forces of structural members. This strength value is therefore an essential parameter in design codes. The test is mainly used as a basis for quality control, in order to ensure that the project requirements are assured [1].

Despite the advantages offered by this test, the need has always arisen to know the resistance that concrete offers "in situ" and due to this situation, alternative methods have been implemented to determine this mechanical property of concrete, and thus, as In 1950 the first sclerometer was designed for the non-destructive measurement of concrete. Patented under the name SCHMIDT, its rebound value "R" allows to measure the hardness of this material. It has become the most widely used procedure in the world, for non-destructive control in concrete [1].
The method used is based on the American Concrete Institute procedure, prepared by the ACI 211 committee, presented by SANCHEZ and since this method is designed for aggregates that meet the grain sizes recommended by ASTM C 33, it is necessary to carry out the particle size optimization of coarse and fine aggregate [2].

Compressive strength is the maximum measure of axial load between the cross sectional area of cylindrical concrete specimens, expressed in the International System in Mega Pascals (MPa) at an age of 28 days [3]. Other ages can be used for testing, but it is important to know the relationship between 28-day resistance and resistance at other ages. 7-day resistance is normally estimated as $75 \%$ of resistance at 28 days and resistance at 56 and 90 days is approximately $10 \%$ and $15 \%$ greater than resistance at 28 days. The compressive strength obtained in concrete is a function of the water-cement ratio, hydration, curing, environmental conditions and the age of the concrete [4].

The test methods normally used to determine the strengths of hardened concrete can be classified as destructive and nondestructive [5].

Strength tests of hardened concrete can be performed under the following conditions: specimens cured and moulded in accordance with ASTM C 31 (AASHTO T 23), NTC 550 and ASTM C 192 (AASHTO T 126), NTC 1377 of concrete samples cool; specimens removed or sawn from the hardened concrete structure in accordance with ASTM C 42 (AASHTO T 24) and NTC 3658 or specimens produced with cast-in-place cylinder moulds (structure), ASTM C 873 [4].

When the results of the compressive strength tests do not meet the prerequisites established in the design, to verify this situation, the structural element is mechanically removed, to later check the real resistance of the structure, as established in NTC 3658 "Method for obtaining and testing extracted cores and sawn concrete beams" [3]. When it is necessary to carry out this test, it must be taken into account that the extraction will be done at a point of the structural element that is not subjected to excessive stresses, preferably where the compression stresses are minimal. The extraction will be located, taking care not to cut the reinforcement, especially the main reinforcement. Once the specimen has been extracted, its hole will be filled with high-resistance concrete, re-shaping, so that it occupies the entire cavity, minimizing the effect of structural weakening. A concrete that does not show volume loss in the setting 
process will be chosen for the filling [6].

Non Destructive Testing (NDT) can be used to assess the relative strength and other properties of hardened concrete. The most widely used are the sclerometer, the penetration, pullout, dynamic and vibration tests. Each method has limitations and care must be taken to accept the results of nondestructive testing as having a constant correlation with the traditional compression test. For example, empirical correlations must be established before using such results [7]. An NDT program can be performed for a variety of purposes, in relation to strength or the condition of hardened concrete, including: determination of strength in situ, control of the rate of development of strength of concrete, location of heterogeneities, such as voids or holes in the concrete, determination of the relative resistance of comparable elements, evaluation of the cracking of the concrete, evaluation of the damage by mechanical forces, location, size and corrosive activity of the reinforcing steel, dimensions of the elements [4].

Through the use of the sclerometer, it is intended to provide an estimate of the compressive strength of concrete, based on the correlation between said strength, with its surface hardness. To determine surface hardness, the rebound value should be measured with the Schmidt hammer or sclerometer [3]. "In this test, the principle is to impact the concrete surface with a certain mass, activated by a certain kinetic energy, and measure the magnitude of the rebound force. Bounce tests are fast and cheap, and also allow studying the surface uniformity of concrete" [8].

In order to obtain an estimate of the compressive strength in situ using a rebound hammer, in accordance with the most important standards, a calibration is required. Testing has shown that the Silver Schmidt can deliver a better correlation, at lower dispersion, than a classic hammer, if calibrated for a specific mix. The recommended method is to correlate the rebound hammer measurements with destructive tests carried out on core samples, or on cubes / cylinders made of the same mixture as the structure [9].

It is recommended to calibrate the hammer for a specific mix design under test and to program a custom curve in the hammer for on-site testing [10].

The default curve of the digital sclerometer is that of the 10th percentile, as shown in Figure 2. It is derived from more than 2300 data points collected under controlled trials by the Federal Institute for Materials and Testing Research in Berlin, Germany, (BAM), Shaanxi Province, China Building Science Research Institute and Hunan University, China. It covers a wide variety of concrete mixes [9].

\section{METHODOLOGY}

The type of research to develop has three differentiable phases. The first phase is descriptive, where a field and laboratory work is undertaken to obtain total information; This consists of the literary review related to the research, a survey carried out to different builders in the region about the origin of the materials they use in the manufacture of concrete and the physicalmechanical characterization, through tests of the coarse aggregate of the geological formations of Toluviejo, of the fine aggregate from the Sinú river (Lorica) and the cement used, in order to carry out the necessary dosages to achieve the compressive strengths of concrete of 17.5 MPa, 21 MPa, 24.5 $\mathrm{MPa}$ and $28 \mathrm{MPa}$.

The second phase includes the start-up of the preparation of the concrete specimens with the dosage obtained in the tests of the previous phase, to carry out the tests of resistance to compression in the cylinder compression machine and the tests for determination hardness with the sclerometer, after curing at $3,7,14,21$ and 28 days, respectively.

The third phase corresponds to correlation and regression studies using the data obtained in the second phase and the use of advanced statistics, using multivariate methods for data analysis, with which it is intended to infer about the behavior of the variables with respect to the compressive strength of concrete.

As the basis for the characterization of the aggregates (coarse and fine), the most important physical and mechanical properties are determined and for the achievement of the concrete cylinders, the respective tests are carried out on cement and concrete, based on the procedures described in the NTC standards of the Colombian Institute of Technical Standards ICONTEC and the current technical standards of the National Institute of Roads of Colombia (INVIAS).

The ACI method is defined for the design of concrete mixing and dosing, for the strengths established at $17.5 \mathrm{MPa}, 21 \mathrm{MPa}$, $24.5 \mathrm{MPa}$ and $28 \mathrm{MPa}$, for the elaboration of standardized concrete cylinders, supported by the Colombian Earthquake Resistant Standard NSR- 10, to determine the average compressive strength required [11].

Four mix designs and granulometric optimizations are developed, each sample of coarse aggregate corresponding with the four resistances studied.

The Colombian Institute of Technical Standards ICONTEC174 , refers to the recommended grain size for coarse aggregate according to nominal sizes and fine aggregate.

When the aggregate does not meet the granulometric requirements of the Technical Standard ICONTEC 174 (ASTM C 33), the mixture of the coarse and fine aggregates must be optimized using the requirements of the Road Note Laboratory.

For the manufacture of the mixture, a mixer with the capacity of a cement bag was used, having separated the portions (previously weighed) necessary for each mixture according to the quantities indicated in the dosage; Then the mixing was carried out, as indicated in the NTC 1377 standard "Preparation and curing of concrete specimens for laboratory tests".

Curing began as soon as the concrete hardened enough that its surface was not affected by the procedure used, approximately 24 hours after it was manufactured. The temperature of the curing water was maintained above $13^{\circ} \mathrm{C}$ and uniformly distributed throughout the mixture and below the ambient temperature, which was approximately $25^{\circ} \mathrm{C}$. The specimens were removed from the pool with water, 2 hours before each test, to carry out the drying and the respective measurements, to subsequently carry out the compression tests. 
For the development of the concrete hardness test, the Silver Schmidt model N digital sclerometer, brand proceq, was used. The NTC-3692 standard establishes the procedure to determine the rebound number using the sclerometer. For this purpose, 20 rebounds per specimen were performed, taking the average of these readings as representative value. For the development of the tests, the Sclerometer was configured with a lower curve of the 10th percentile, a carbonation factor of 1.00 and a 2: 1 form factor were used.

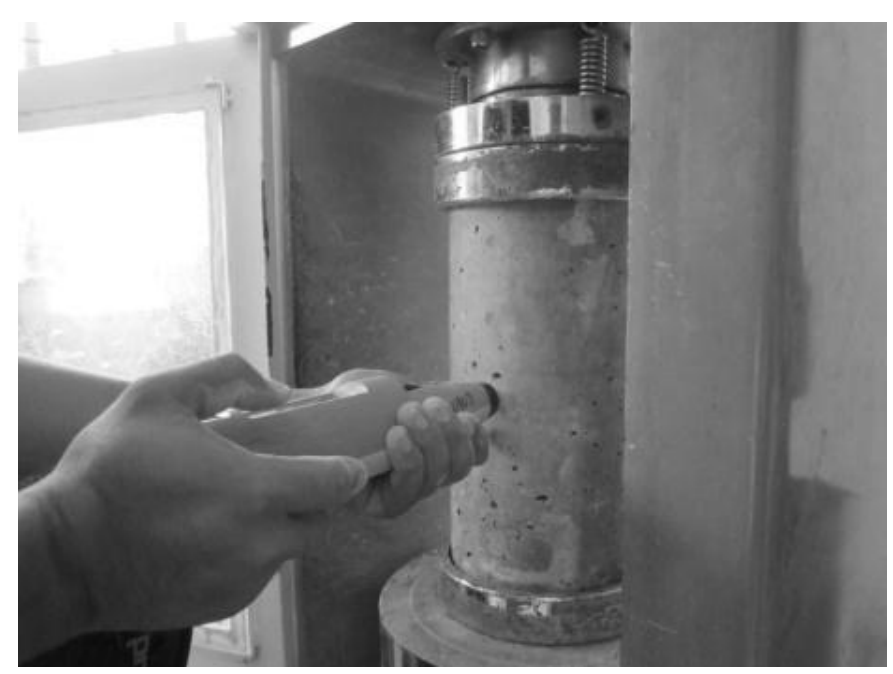

Fig. 1. Sclerometer test

The simple compression test of the concrete cylinders was carried out in accordance with the procedure established in the NTC 673 standard "Compressive strength test of cylindrical concrete specimens".

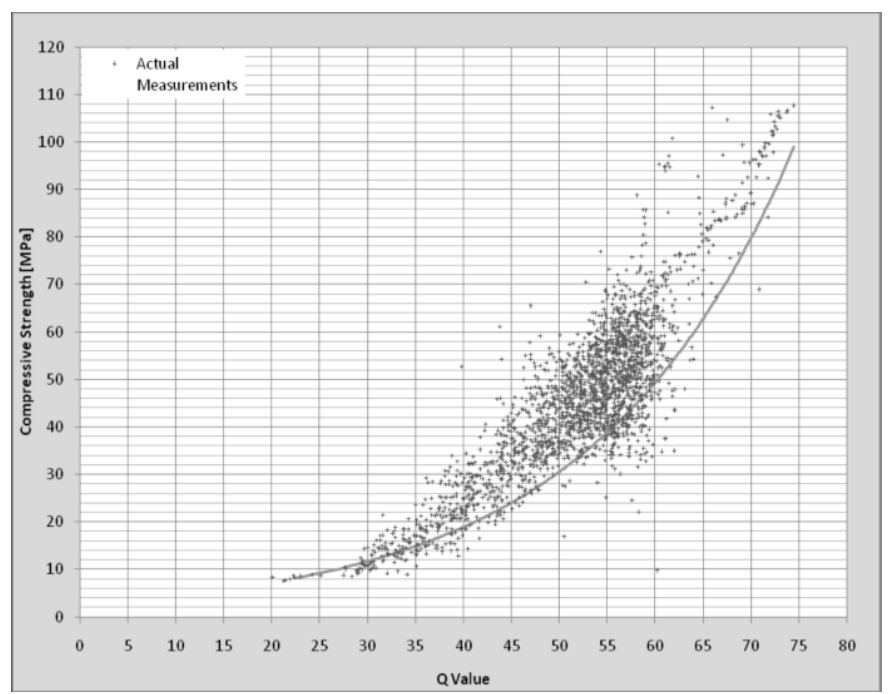

Fig. 2. 10th percentile curve

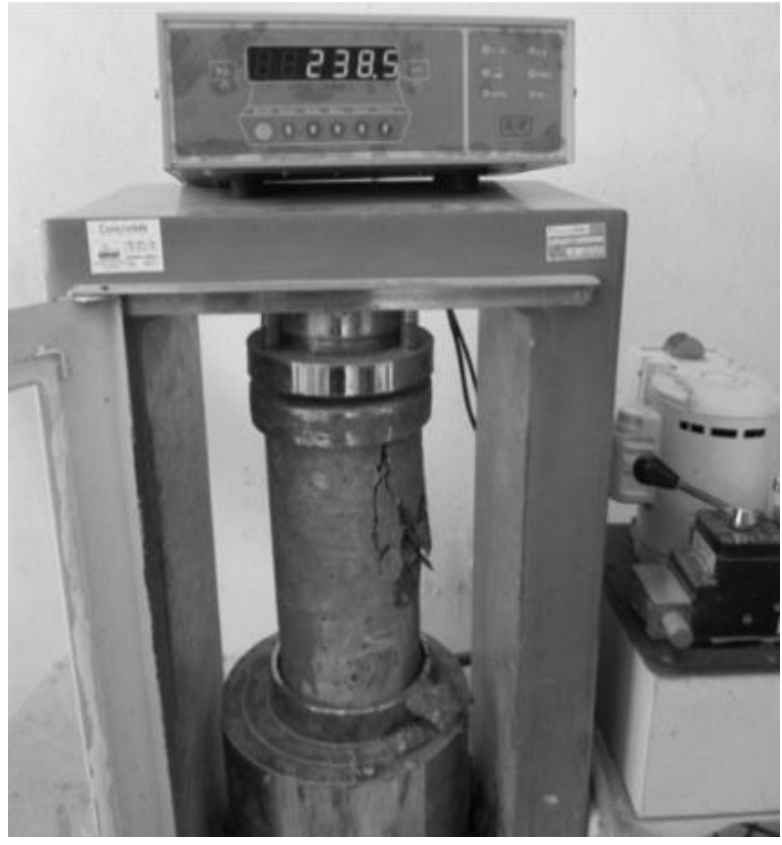

Fig. 3. Test on the compression machine

Dependent variable: Resistance.

Factors: Theoretical resistance, Method, Cured

The sample size was 1200 cylinders

\section{RESULTS}

The results obtained are presented below:

\section{NON LINEAR REGRESSION - MACHINE}

Dependent variable: Machine

Independent variables: sclerometer

Function to estimate:

M: value of the compressive strength of the compression machine $\mathrm{a}$ and $\mathrm{b}$ : parameters to calculate

$\mathrm{E}$ : value of the compressive strength of the sclerometer Estimation method: Marquardt

The estimation was stopped due to the convergence of the sum of squares of residuals.

Number of iterations: 17

Number of calls of the function: 65 .

Table 1. Estimation Results

\begin{tabular}{|c|c|c|c|c|}
\hline Parameter & Dear & $\begin{array}{c}\text { Asymptotic } \\
\text { Standard } \\
\text { Error }\end{array}$ & $\begin{array}{c}\text { Confidence } \\
\text { Interval to } \\
\text { Lower } \\
\text { Asymptotic }\end{array}$ & $\begin{array}{c}95.0 \% \\
\text { Superior }\end{array}$ \\
\hline A & 5.2498 & 0.1246 & 5.0050 & 5.4945 \\
\hline B & 0.0988 & 0.0019 & 0.0949 & 0.1027 \\
\hline
\end{tabular}

Source: Statgraphics Program Analysis 
Table 2. Analysis of Variance

\begin{tabular}{|c|c|c|c|}
\hline Source & $\begin{array}{c}\text { Sum of } \\
\text { squares }\end{array}$ & Gl & $\begin{array}{c}\text { Middle } \\
\text { Square }\end{array}$ \\
\hline Modelo & 144333.0 & 2 & 72166.3 \\
\hline Residuo & 2158.3 & 598 & 3.6 \\
\hline Total & 146491.0 & 600 & \\
\hline Total (Corr.) & 10451.4 & 599 & \\
\hline
\end{tabular}

Source: Statgraphics Program Analysis

R-Square $=79.3487 \%$

R-Square (adjusted by g.1.) $=79.3142 \%$

Standard error of the est. $=1.89981$

Absolute mean error $=1.49586$

Durbin-Watson statistic $=0.968905$

Residual autocorrelation of delay $1=0.509986$

The output shows the results of fitting a nonlinear regression model to describe the relationship between Machine and an independent variable. The equation of the fitted model is:

$\mathrm{M}=5.24981 \mathrm{e}^{0.0988238 \mathrm{E}}$

Table 2. Waste Analysis

\begin{tabular}{|c|c|c|}
\hline & Estimate & Validation \\
\hline $\mathrm{N}$ & 600 & \\
\hline $\mathrm{CME}$ & 3.60926 & \\
\hline MAE & 1.49586 & \\
\hline MAPE & 11.536 & \\
\hline ME & -0.0266435 & \\
\hline MPE & -2.95314 & \\
\hline
\end{tabular}

Source: Statgraphics Program Analysis

By making the adjustment, the estimation process ended successfully after 17 iterations. At this point, the estimated coefficients converged with the current estimates.

The R-Square statistic indicates that the model, thus adjusted, explains $79.3487 \%$ of the variability in Machine. The adjusted R-Square statistic, which is more suitable for comparing models with different number of independent variables is $79.3142 \%$. The standard error of the estimate shows that the standard deviation of the residuals is 1.89981 . This value can be used to construct prediction limits for new observations by selecting the Forecasts option from the text menu. The mean absolute error (MAE) of 1.49586, is the average value of the residuals. The Durbin-Watson (DW) statistician tests the residuals to determine if there is any significant correlation based on the order in which they were presented in your data file.

The output also shows the asymptotic intervals of the $95.0 \%$ confidence intervals for each of the unknown parameters. It is observed that the intervals do not contain 0 , which indicates that the estimation of the coefficients A and B are significant, indicating that the model is good. This is corroborated by the value of the probability of the Durbin-Watson statistic, which is greater than 0.05 .

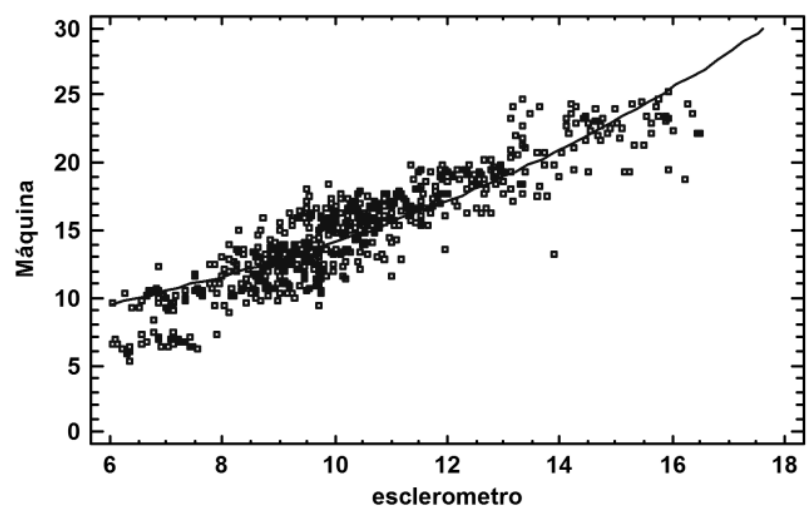

Fig. 4. 10th percentile curve Source: Statgraphics Program Analysis

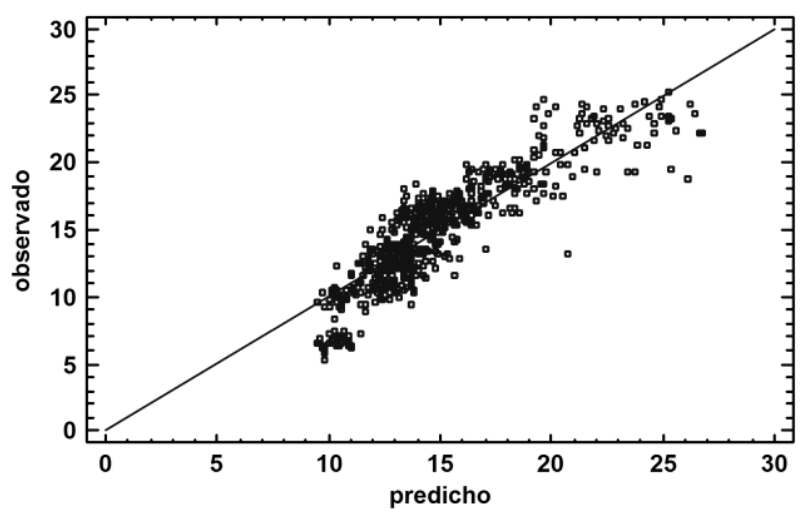

Fig. 5. Machine Graph Source: Statgraphics Program Analysis

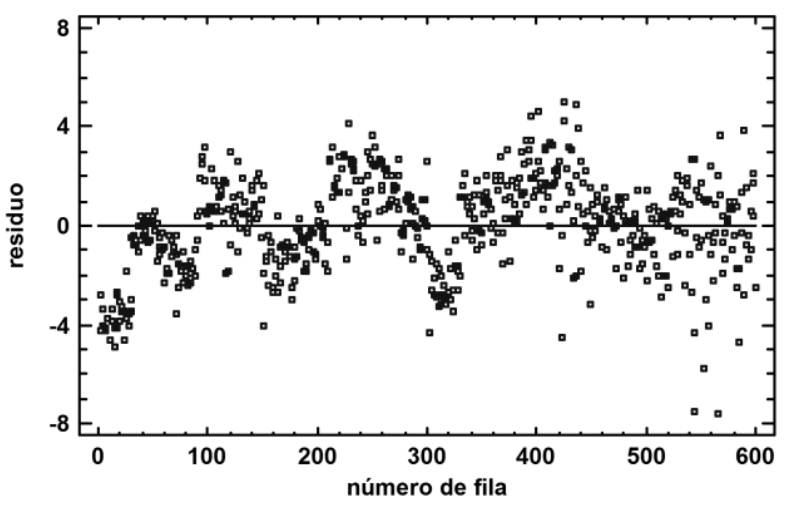

Fig. 6. Waste Graph Source: Statgraphics Program Analysis 


\section{CONCLUSIONS}

In the mix designs that were carried out in this investigation, satisfactory results were found for each of the strengths of 17MPa, 21MPa, 24.5 MPa and 28 MPa.

The readings obtained from the sclerometer were lower than those given by the compression resistance machine, in a difference of around $20 \%$, which is due to the conditions of the concrete specimen (shape, carbonation, curing, drying) and the materials used in the mix design, since the reference curves provided by the manufacturer have been made with materials specific to their area, which could have different physical and mechanical properties than those used in this research project.

According to the results obtained from the multifactorial design, it can be said that there is a $95 \%$ confidence level on the final resistance through the methods used, which means that the factors are related and have an incidence on the final resistance that is not a product of coincidence.

Regarding the correlation that exists between the resistance determination methods by means of the sclerometer and the compression machine, it can be affirmed that both the linear and non-linear models are adjusted; because both explain in a significant percentage, the variability of the resistance values. However, it can be concluded that the non-linear model presents a better fit, because the Durbin-Watson statistic is greater than 0.05, indicating a non-random trend of the residuals; unlike the linear model, where this measure of serial correlation in the residuals is less than 0.05 , which is indicating that the model has not taken into account the entire structure of the data.

Finally, the equation that represents the correlation model is:

$$
\text { Machine }=5.24981 \mathrm{e}^{0.0988238 * \text { ESCLEROMETRO }}
$$

\section{REFERENCES}

[1] www.biblioteca.udep.edu.pe/bibvirudep/tesis/pdf/1_153_ 164_104_1437.pdf.

[2] Sánchez D. "Tecnología del concreto y del mortero". Brandar Editores Ltda. Colombia. Quinta edición, (2001).

[3] Asocreto. "Tecnología del concreto", Nomos impresores, Tomo 1, Tercera edición, Colombia. (2010).

[4] Kosmatka S, "Diseño y Control de Mezclas de Concreto", Portland Cement Association, Skokie, Illinois, EE.UU., (2004).

[5] Montoya J, "Hormigón Armado", Bellisco Ediciones, España, (2008).

[6] Trujillo J, "Transporte y vertido de hormigones (UF0200)". IC Editorial, España, (2013).

[7] Malhotra VM and Carino NJ. "Handbook on nondestructive testing of concrete". CRC Press, Boca Raton, U.S.A., (1991).

[8] Miranda J, "Corrosión en las estructuras de hormigón armado", Editorial Consejo Superior de Investigaciones Científicas. España, (2008).
[9] www.proceq.com/uploads/tx_proceqproductcms/import_ data/files/SilverSchmidt_Operating_Instructions_Spanish _high.pdf (2015).

[10] www.proceq.com/en/nondestructivetestequipment.html (2015).

[11] Ministerio de ambiente, Vivienda y Desarrollo Territorial, "Normas colombianas de diseño y construcción sismo resistente NSR-10”. Colombia, (2010). 